\title{
Infográficos como recurso auxiliar do processo de aprendizagem de estudantes do ensino médio
}

\begin{abstract}
RESUMO
Mudanças observadas no cenário da educação através da utilização de recursos midiáticos vislumbram as múltiplas formas de aprender e disseminar o conhecimento, buscando adequar as ferramentas surgidas em outros contextos para aplicar no âmbito da sala de aula, como os infográficos. Dessa maneira, a pesquisa tem por objetivo analisar a percepção dos estudantes sobre a criação e utilização de infográficos como recurso para auxiliar a aprendizagem. Fundamenta-se nos seguintes autores: Charlot (2000), Meireu (1998), Horn (1998), Colle (2004), Behrens (2005), Minervini (2005), Schmitt (2006), Leontiev (1978; 2006) entre outros. Quanto a metodologia trata-se de uma pesquisa descritiva, a qual foi desenvolvida em uma escola da rede pública estadual de Pernambuco, na disciplina de Química, no segundo e terceiro ano do ensino médio. O estudo utilizou uma sequência didática (SD) de acordo com Zabala (1998). Participaram da SD 43 estudantes do segundo ano e 36 do terceiro ano. A SD foi proposta em quatro etapas, a primeira apresenta uma abordagem sobre infográficos, a segunda é o momento prático em que os estudantes constroem os infográficos, a terceira é da exposição dos infográficos construídos e o processo de avaliação, e a quarta etapa culmina com aplicação do questionário com cinco questões objetivas. Todos os estudantes participaram da SD, exceto da etapa do questionário que foi aplicado por amostragem com 15 estudantes do segundo ano e 15 do terceiro ano. Os resultados demonstraram que 07 educandos do segundo e 11 do terceiro conheciam sobre infográfico, mas não sabiam construí-lo; em relação ao recurso auxiliar na aprendizagem, 07 estudantes do segundo e 10 do terceiro responderam que auxilia de forma parcial; no que se refere aos aspectos mais apontados na criação de infográficos os mais citados foram: autonomia, curiosidade e criatividade. As dificuldades expressas foram em relação à organização das informações nos modelos dos aplicativos/programas. Portanto, os infográficos emergem como uma ferramenta inovadora, pois os estudantes sentem-se atraídos por essa nova forma de conduzir o aprendizado, no entanto, ainda estão pouco habituados ao recurso o que requer mais exploração para integrá-lo às situações escolares.
\end{abstract}

Karla Jeane Vilela de Oliveira biokarlalogia@gmail.com 0000-0002-7753-8875 Universidade Federal de Pernambuco, Caruaru, Pernambuco, Brasil.

Kátia Silva Cunha kscunha@gmail.com 0000-0001-9282-715X Universidade Federal de Pernambuco, Caruaru, Pernambuco, Brasil.

PALAVRAS-CHAVE: Aprendizagem. Infográficos. Recurso Didático. 


\section{INTRODUÇÃO}

Os aspectos oriundos da educação no século XXI concebem vicissitudes impregnadas de recursos tecnológicos digitais, às quais o professor precisa adequar-se as diversas formas de desenvolver suas práticas docentes para abranger os diferentes estilos de aprendizagem discentes.

Assim, emerge a infografia no âmbito escolar como recurso que auxilia o ensinar e o aprender, porque "a produção do conhecimento com autonomia, com criatividade, com criticidade e espírito investigativo provoca a interpretação do conhecimento e não apenas a sua aceitação" (BEHRENS, 2005, p. 55). Essas características são importantes na medida em que se associam para expressar as informações que são de interesse e que corroboram para o processo educativo. Mas, afinal, o que é infografia?

Ao explicar sobre infografia, Ribeiro (2008) afirma que o termo vem do inglês infographic e que é uma forma simplificada das palavras information graphic, que em sua tradução para o português significa informação gráfica. Os infográficos são ferramentas que auxiliam o entendimento da informação por texto e imagem. Assim, compreender os aspectos que impregnam a criação desse recurso requer entendimento de algumas características da linguagem visual (HORN, 1998), do design e da síntese de informações que se quer apresentar.

Com a demanda das Tecnologias Digitais da Informação e Comunicação (TDIC), que adentram o contexto educacional, têm-se ampliado as maneiras de abordagem e interações na sala de aula e fora dela. De acordo com Mattar (2013, p. 115), surge "um canal de comunicação mais aberto, resultando em ambientes de aprendizagem mais ricos e maior envolvimento dos alunos nos processos de escolarização". Nesse viés, aparecem as tecnologias digitais e redes de informações possibilitando novos espaços mais flexíveis de aprendizagem.

Assim, o impacto da TDIC implica em processos de ensino e aprendizagem de forma colaborativa, o que exige que tanto estudantes como professores participem das atividades trazendo uma série de percepções sobre o mesmo conteúdo. Corroborando com esse pensamento, Moran (2013) afirma que é preciso reformular a educação, identificando novas formas e espaços para ensinar e aprender. Dessa maneira, compreender novas ferramentas, metodologias e mudanças na didática são fatores imprescindíveis para o processo educacional.

Nesse contexto, algumas ferramentas quando bem orientadas podem colaborar no processo educacional e consequentemente na construção de infográficos, como: o computador e o smartphone. De acordo com Valente (1997, p. 19) o "computador na educação é justamente aquele que tenta provocar mudanças na abordagem pedagógica [...]". É um instrumento que pode desencadear novas formas de realizar a prática de ensino quando o docente passa a ver esse equipamento como um recurso a mais na sua aula. Nessa perspectiva também, inserimos o uso de dispositivos tecnológicos, os smartphones.

O uso de smartphones amplia as possibilidades educacionais quando bem programados seus momentos de aplicação (SILVA JÚNIOR, 2017). Dessa forma, a utilização desses aparelhos necessita de inserção no planejamento docente e no contrato didático para que sua aplicação realmente atenda os objetivos propostos. Tanto computadores como smartphones contribuem para a elaboração de infográficos, oferecendo programas, aplicativos ou ainda modelos que facilitam a 
interação dos aprendizes com o conteúdo proposto, no qual com base em exemplos, conhecimento, pesquisa e criatividade criarão seu próprio material.

A respeito desses instrumentos podem-se ter novas maneiras de explorar a abordagem de conteúdos e usar a infografia, principalmente no âmbito educacional por meio das tecnologias digitais que amplificam os recursos gráficos e os contextos informativos (CAIRO, 2008). As tecnologias digitais facilitam na correlação de informações e ferramentas para a produção de materiais didáticos.

Nesse contexto, Moran (2013) aduz que a era digital, a comunicação em rede e suas formas de atuar têm influenciado as mudanças na educação. Metodologias e recursos de ensino colaboram com a aprendizagem dos estudantes, produzindo uma gama de conteúdos que podem ser visualizados por tantos indivíduos, de acordo com o que buscam como fonte de conhecimento.

Destacamos, pois, que o objetivo desse artigo é analisar a percepção dos estudantes sobre a criação e utilização de infográficos como recurso para auxiliar a aprendizagem. Perante esse contexto, como aponta o trabalho de Lima e Catelão (2019), o indivíduo é visto como alguém curioso, e é de se esperar que não se contente com $o$ que é transmitido, mas com $o$ que pode encontrar/explorar/descobrir com sua curiosidade.

Esse artigo se fundamenta nos seguintes autores: Charlot (2000), Meireu (1998), Horn (1998), Colle (2004), Behrens (2005), Minervini (2005), Schmitt (2006), Leontiev $(1978 ; 2006)$ entre outros. Tem como metodologia a sequência didática proposta por Zabala (1998) e no que concerne à estruturação, apresentase dividido em: aspectos teóricos metodológicos dos infográficos; concepção da aprendizagem com a criação e uso de infográficos; a metodologia, os resultados e discussão, e por fim as considerações finais.

\section{ASPECTOS TEÓRICOS E METODOLÓGICOS DOS INFOGRÁFICOS}

Os infográficos começaram a ser utilizados em jornais (CAIRO, 2008). Hoje vemos o quanto está disseminado em outros âmbitos, como, por exemplo, na educação, para apresentar e explicar conteúdos ou ainda para divulgar informativos nesse âmbito. Os infográficos, no jornalismo, surgiram como a própria linguagem jornalística ao resumir textos escritos e impregná-los de outros caracteres que diminuem o excesso do texto facilitando a leitura.

Apesar de os infográficos serem constantemente associados à junção de textos e imagens há quem defina diferente, como Lucas (2011, p. 211), o infográfico é "[...] um tipo de produção que articula, de um modo específico e espacial, textos verbais, imagens de diversas naturezas e elementos visuais (cores, números, setas, fios, etc.)". Na concepção do autor, os elementos visuais não estão englobados nas imagens, mas vistos de modo distinto, representando outro viés.

Nesse estudo, no entanto, não temos o objetivo de identificar qual a melhor definição para infográfico, afinal, como esse está sendo disseminado para outros meios, além do jornalístico e do design, é inevitável que haja diferentes concepções alocadas para cada especificidade do âmbito que o adote. $O$ que parece convergir, porém, é o fato do infográfico ser um dos meios mais fáceis de propagar informações. 
Diante do exposto, a linguagem visual proporciona, por vezes, maior envolvimento por representar o texto em conjunto com imagens e/ ou formas (HORN, 1998). Desse modo, entende-se, segundo o autor, que os infográficos têm como principal característica essa linguagem como canal de comunicação dotado de significados. Na concepção de Horn (1998) há maneiras claras de direcionar um infográfico para atender o leitor como mostrado na figura 1, assim, o autor propõe que a linguagem visual deve considerar:

Figura 1 - Fatores importantes da linguagem visual

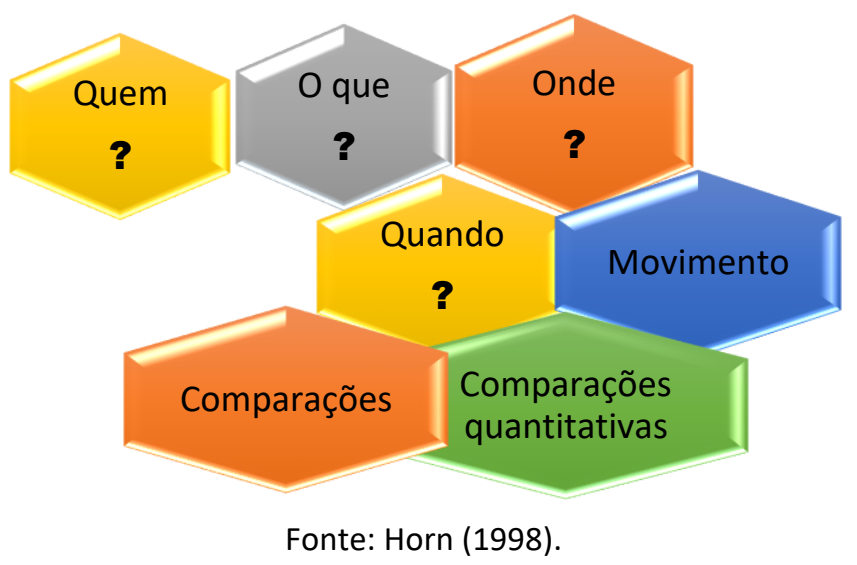

Esses fatores implicam no tipo de informação que se quer passar para o leitor. Vale ressaltar que, para toda construção de infográficos é necessário ter a definição do tema, a pesquisa sobre o assunto, quais tópicos serão abordados, a esquematização de como será disposto o conteúdo. Além disso, também é importante a criação de um protótipo, a escolha dos elementos gráficos e uma revisão da configuração final.

Dentro dessa ótica, Schmitt (2006) considera a utilização dos infográficos como um recurso para representar conteúdos tecnológicos e científicos que trazem esse caráter mais complexo de entendimento, sendo um meio mais atrativo de disseminação da informação. A esse respeito, Minervini (2005, np) aponta que os infográficos "impactam as formas de acesso e apropriação do conhecimento" procurando expor de maneira mais acessível, temas de importância para os leitores.

Na concepção de Teixeira (2007), toda a estrutura de um infográfico deve fazer sentido para quem visualiza, para sua compreensão, sem um ou outro aspecto do discurso ser favorecido, ou seja, eles devem se complementar ao invés de um ser hierarquizado. "Assim, atingem mais leitores, pois, se encaixam adequadamente ao seu estilo de vida, proporcionando, inclusive, mais agilidade ao processo de recepção textual" (CALEGARI; PERFEITO, 2013, p. 297). As imagens agregadas às informações mais precisas, apresentadas no formato de infográfico, tentam facilitar a compreensão do leitor de um modo mais rápido.

Para Dondis (2000) é a linguagem visual que manifesta quase que automaticamente a mensagem. Cada pessoa assimila aspectos distintos, mas em conjunto, de um mesmo infográfico, para compreender a informação. A relação entre imagens, textos e outros caracteres de modo imbricado expõem o que se quer que o outro entenda. Por isso, há diversas categorias de infográficos: os informativos, científicos, publicitários, corporativos, os de apresentação de 
projetos e os didáticos (COLLE, 2004). A respeito dos infográficos didáticos o autor explica que:

[...] seu uso no campo educacional ainda é recente e muito imaginário. Tem dois aspectos, por um lado, seu uso em sala de aula como forma de apresentar informações e atrair a atenção dos alunos; e por outro lado, trazer o aluno à sua elaboração e, assim, desenvolver nele as habilidades de procurar, obter e processar as informações ou, em outras palavras, desenvolver a competência digital e tratamento de informações (tradução nossa) (COLLE, 2004, p. 13).

A produção de infográficos demonstra como o estudante pode desenvolver algumas competências, sejam de leitura, interpretação de textos, de correlações de informações, tendo interação com recursos digitais, desenvolvendo habilidades tecnológicas e oportunidade de colaborar para disseminação de assuntos que são de interesse da população. A infografia é um recurso que pode ser introduzido tanto para verificar conceitos prévios como para o percurso de construção da aprendizagem.

Os infográficos trazem a multimodalidade, que conforme Dionísio (2007), são construções textuais em que recursos verbais e visuais estão em conexão para produzir o discurso. Essa representação de vários elementos na composição de textos tem se garantido pelos instrumentos tecnológicos digitais que fazem essa hibridização de linguagens. Essa colocação reflete a mesma encontrada por Schmitt:

\footnotetext{
A infografia também pode ser compreendida como um sistema híbrido de comunicação, pois ao empregar imagens, palavras e números, utiliza o sistema de comunicação verbal (palavras e sentenças) e o sistema de comunicação visual (imagens e representações gráficas) (SCHMITT, 2006, p. 18).
}

A elaboração de materiais gráficos pode contribuir com o alcance de competências e habilidades necessárias para formação integral do educando. Podemos dizer que vai muito além do citado, corresponde a utilização de múltiplas inteligências como bem afirma Reinhardt:

\footnotetext{
Não temos que nos limitar a uma educação puramente lógica-racional, negando que existam outras capacidades mentais que precisam ser desenvolvidas, como ser artístico, emocional, criativo, perceptivo e relacional; que permitem um desenvolvimento integral do ser (tradução nossa) (REINHARDT, 2010, p. 126)
}

Compreender que o indivíduo apresenta diferentes formas de aprender um conteúdo requer também novos meios de ensinar, e para isso são necessárias mudanças de atitudes nas metodologias e recursos utilizados pelos professores. Na visão de Reinhardt (2007), os infográficos são promotores da construção da aprendizagem na medida que envolvem diversas habilidades na sua produção, implicando na formulação do conhecimento através da capacidade crítica e criativa que as informações podem levar.

Nesse contexto, Muñoz Carril, Fuentes Abeledo e González Sanmamed (2012) explicam que elaborar materiais pedagógicos com auxílio de recursos multimídia exige uma relação de vários fatores desde aspectos conteudistas até de design. A construção de infográficos propõe a apresentação de esclarecimentos através da 
leitura de imagens, da visualização de cores e da forma de estruturação que implica na organização das informações.

Corroborando com as explicações de Muñoz Carril, Fuentes Abeledo e González Sanmamed (2012), Feerés (1989, p. 89 apud MINERVINI, 2005) afirma que "se a escola quiser construir uma ponte com a sociedade, terá que assumir plenamente o audiovisual como uma forma de expressão diferenciada". Os infográficos estão evoluindo graças aos aspectos oferecidos pelas tecnologias digitais que trazem novos formatos, mais interativos e animados, basta que se saiba utilizar os recursos computacionais disponíveis.

Esses recursos aplicados a um campo rico em materiais de divulgação e com o auxílio da mídia gráfica implantam mecanismos diversos, abrangendo leitores que estão imersos em novos ou ressignificados formatos de compreensão de informações (MINERVINI, 2005). Essa maneira de trabalhar o conteúdo desperta a criticidade, a capacidade de associação e de interpretação, de acordo com os diferentes arquétipos dos educandos na sua forma de entender determinadas informações, e também, de comunicar um assunto através do infográfico que se insere na sala de aula.

O ensino através da infografia defende a descoberta/exploração de conteúdos, tendo em vista que, esses termos estão vinculados ao desenvolvimento da autonomia do educando no seu processo de aprendiz. Na produção de infográficos o "[...] aluno toma ciência de seu potencial de transformação no processo de ensino-aprendizagem e pretende-se que ele o use [...] a fim de produzir conhecimento, tomar sua autonomia" (LIMA; CATELÃO, 2019, p. 14). O pensamento crítico com a capacidade de síntese compõe essa autonomia, tornando-o protagonista do seu conhecimento.

Quando se pede para um grupo de estudantes elaborarem um infográfico cada um apresenta um pouco das suas concepções, das suas particularidades, alguns dão palpites na configuração, nas cores, nos elementos gráficos, imagens, disposição do texto, outros já terão mais habilidade na síntese das informações. Dessa forma, todos contribuem e aprendem de formas diferentes o mesmo conteúdo, pois, cada um tem sua perspectiva de organização, mas encontram um meio de incluir os aspectos oriundos das diversas possibilidades de ver, compreender e organizar um tema.

Nesse sentido, Alvarez (2012) afirma que trabalhar em grupo, organizar e sistematizar as informações, demonstra habilidades de representação visual com ferramentas tecnológicas para assim comunicar ao leitor determinado conteúdo. É importante compreender que a imagem é algo representativo que se pode obter várias informações a respeito da mesma, pois, depende de como, do que se observa e o que consegue ser extraído. Corroborando com esse pensamento, Cepeda (2019) diz que a imagem é uma importante característica para aprendizagem e o trabalho didático, por encantar e prender a atenção para que o conteúdo seja disseminado.

A utilização de infográficos como ferramenta de ensino e aprendizagem vem inferir em um contexto de mudanças nas situações didáticas, bem como no processo de avaliação, vislumbrando uma forma de relacionar visões diferentes em um mesmo instrumento através de como são construídos e apresentados. Nessa perspectiva, Alvarez (2012) aponta o professor como mediador 
comprometido com as inovações nas práticas pedagógicas, que necessita buscar recursos que valorizem as diferentes formas de aprendizagem dos educandos.

Ensinar através de situações que levem os estudantes a adentrarem ao conteúdo de uma forma diferente das aulas expositivas requer novas formas de expô-lo, de ressaltar o que os estudantes já sabem e orientar na construção do conhecimento ou ressignificação do mesmo. Esses pontos e os objetivos claros sobre as atividades trazem um constante processo de interação, professor e estudante, auxiliando nas dificuldades que aparecem no cenário educativo (CARVALHO; PEREZ, 2001).

De acordo com Zabala (2011), outro ponto que vale salientar no processo educativo é a avaliação, a qual depende da forma como as estratégias didáticas foram trabalhadas. Ao se utilizar meios diferenciados de avaliação pode-se ter uma percepção diferente de como o estudante está aprendendo, bem como ter um referencial se as estratégias didáticas utilizadas em aula estão sendo eficazes na aprendizagem. Dessa forma, pode-se propor outras ferramentas e situações de ensino, caso não estejam surtindo efeito esperado.

\section{CONCEPÇÃO DA APRENDIZAGEM COM A CRIAÇÃO E USO DE INFOGRÁFICOS}

De forma específica as teorias trazem pressupostos que de uma maneira ou de outra buscam explicar como o estudante aprende, e oferecem subsídios aos professores que podem interferir no método como se ensina.

Descrever diversas formas de aprendizagem é encontrar aportes teóricos que significam de modo particular o que é aprender. Para Charlot (2000, p. 53), por exemplo, "[...] aprender, é entrar em um conjunto de relações e processos que constituem um sistema de sentido, onde se diz quem eu sou, quem é o mundo, quem são os outros". Essas conexões que se estabelecem na produção da aprendizagem são muito específicas, pois, cada pessoa está inserida em contextos diferentes.

No mundo de comunicações cada vez mais rápidas em que muitas vezes é necessário aprender mais em curto espaço de tempo tem-se promovido vicissitudes na aprendizagem. Nesse âmbito de transformações que se processam nos tempos atuais, Fonseca (1998) traz o que ele denomina de "adaptabilidade de modificabilidade" - característica de preocupar-se com as evoluções no contexto da humanidade, as condições de mudanças tecnológicas e os possíveis dilemas que surgem com qualquer transição.

Além disso, é o desejo fator primordial para o aprender (MEIRIEU, 1998). Em outras palavras, pode-se dizer que "passar da significação ao valor supõe que se considere o sujeito enquanto dinâmica do desejo" (CHARLOT, 2000, p. 82). Assim, não basta apenas ter sentido, mas fazer desse uma ação para que se aprenda. $A$ aprendizagem emerge da superação das dificuldades que estão relacionados aos tipos de procedimentos metodológicos e avaliativos aplicados.

Pode-se não compreender em um dado momento ou da forma que gostaria, mas há sempre oportunidade de aprender de outra maneira, em outro contexto, com outro desejo. "Aprender é passar da não-posse a posse, da identificação de um saber virtual à sua apropriação real” (CHARLOT, 2000, p. 86). A identificação só ocorre se estiver alicerçada a algo que tem utilidade para o sujeito, pois, desse 
modo, surge a compreensão. A informação e sua aplicabilidade produzem significados que levam à verdadeira aprendizagem, nesse contexto as atividades devem ser geradoras de sentido para o sujeito (MEIRIEU, 1998).

Dessa maneira, a aprendizagem, de fato, ocorre quando há um efeito positivo para o sujeito, quando este sente-se motivado por fazer de um objeto o seu interesse (MEIRIEU, 1998). Concordando com esse posicionamento Charlot (2000, p. 82) afirma o seguinte: "[...] é porque o sujeito é desejo que sua relação com o saber coloca em jogo a questão do valor do que ele aprende". A partir dos discursos apresentados pelos autores citados o que é aprendido deve ajudar na elucidação de situações diversas para que se torne relevante para quem o faz.

Compreende-se, assim, que o estudo da aprendizagem está envolto de diversos fundamentos que buscam explicar como ser humano aprende. Como expressa Moreira (1999, p. 12), teoria da aprendizagem é "uma construção humana para interpretar sistematicamente a área de conhecimento que chamamos aprendizagem". Desse modo, buscamos entender como a teoria histórico cultural, na perspectiva Vigotski e do desenvolvimento da teoria da atividade de Leontiev, contribuem para os processos educativos utilizando a construção dos infográficos.

A teoria histórico cultural emergiu em um período em que a União Soviética passava por vicissitudes pautadas nas mudanças sociais, com uma nova concepção de educação, considerando o homem como ser um ser proativo (PRESTES; LOPES, 2015). Ainda segundo as autoras, essa teoria sofreu repressão em alguns momentos do seu decurso histórico, mas tem sido utilizada em estudos atuais por representarem contextos contemporâneos baseados principalmente em Vigotski, Luria, Leontiev e outros.

A teoria da atividade surgiu do conceito proposto na teoria histórico cultural, e apesar de Vigotski o ter apontado em seus estudos precursores, "foi Leontiev quem o sistematizou, fundando a teoria psicológica da atividade. Esse conceito desempenha as funções de princípio explicativo dos processos psicológicos superiores e de objeto de investigação" (ASBAHR, 2005, p. 109). É a partir da atividade que compreendemos e desenvolvemos capacidades e habilidades de modificação de uma realidade.

Segundo Asbahr (2005) o conceito de atividade é visto pelos psicólogos soviéticos como fator para a explicação do desenvolvimento da consciência. Dessa maneira, atividade e consciência são apresentadas como constituintes da psicologia histórico cultural (Idem). Corroborando com essa linha de pensamento, Ostermann e Cavalacanti (2011) afirmam que a atividade desenvolve as aptidões mentais superiores, e citam que Vigotski a ressalta como o processo que transforma o meio com base nos instrumentos e signos.

O sujeito usa instrumentos e signos para a transformação do objeto a partir da internalização. O contexto social e cultural (sistema semiótico, conjuntos de signos para a comunicação e representação da realidade) contribuem para a formação do desenvolvimento psíquico do indivíduo (OSTERMANN; CAVALCANTI, 2011). Ainda é importante ressaltar que as relações de colaboração, de estabelecimento de vínculos emocionais, das valorizações de subjetividades e do mundo intrínseco e extrínseco dos indivíduos só terá sentido com atividade. 
A mediação de outras pessoas para que o indivíduo desempenhe uma tarefa e a forma independente de resolvê-la são aspectos da zona de desenvolvimento proximal (ZDP), esse conceito indica que o progresso individual se dá na realização de determinada atividade e na interação com outras pessoas para realizá-la (OSTERMANN; CAVALCANTI, 2011). Na concepção de Querol, Cassandre e Bulgacov (2014) a ZDP antecipa as capacidades do desenvolvimento que ainda serão vivenciadas no individual e no coletivo.

Nesse sentido, a utilização de artefatos e a relação social e cultural promove uma internalização que provoca desenvolvimento que não se prende apenas ao contexto no qual o sujeito está inserido, mas abre caminhos para novas possibilidades (QUEROL; CASSANDRE; BULGACOV, 2014). Considerando a perspectiva vigotskiana, o professor tem um papel essencial nas interações provocadas pelos signos e instrumentos utilizados no decorrer da aula para a promoção do aprendizado (OSTERMANN; CAVALCANTI, 2011).

Trazendo outro enfoque, Asbahr (2005) explica que a necessidade e as emoções juntamente aos processos cognitivos trazem significado para a atividade. Para Leontiev (2006) a atividade é dirigida pelo processo que faz sentido para o estudante realizá-la, o objeto e o motivo precisam estar atrelados por ações mobilizadoras para que ocorra.

Diante do exposto, a teoria da atividade se relaciona à escola pelo motivo do aprender. O motivo direciona a atividade do aluno para que ele seja proativo em sua aprendizagem (GRYMUZA; RÊGO, 2014). Para Leontiev (2006) existe dois tipos de motivo: os compreensíveis e os eficazes, os quais Grymuza e Rêgo apresentam como,

[...] 'motivos-estímulos' ou 'motivos formadores de sentido'. Os primeiros mobilizam o indivíduo por critérios que não estão relacionados diretamente ao objeto da atividade. Já os motivos formadores de sentido mobilizam a atividade segundo critérios que efetivam a relação de necessidade com o objeto (GRYMUZA; RÊGO, 2014, p. 23).

Nesse viés, o significado se dá no sentido, ou seja, é necessário que algo faça sentido para ter significação pessoal, a sociedade é cheia de significações, mas é na relação com essa que o conhecimento é internalizado (LEONTIEV, 1978). Assim,

\footnotetext{
A significação mediatiza o reflexo do mundo pelo homem na medida em que ele tem consciência deste, isto é, na medida em que o seu reflexo do mundo se apoia na experiência da prática social e a integra. [...] Assim psicologicamente, a significação é, entrada na minha consciência (mais ou menos plenamente e sob todos os seus aspectos), o reflexo generalizado da realidade elaborado pela humanidade e fixado sob forma de conceitos, de um saber ou mesmo de um saber-fazer ("modo de acção" generalizado, norma de comportamento, etc.) (LEONTIEV, 1978, p. 95-96).
}

Essas concepções ajudam na compreensão dos aspectos de aprendizagem envoltos na produção e utilização de infográficos como recurso educacional. Esse recurso depende exatamente do que é internalizado, das relações de mediação, das ações mobilizadoras, da necessidade e do motivo, propondo um instrumento dotado de significações e significado. 


\section{METODOLOGIA}

O estudo em questão é uma pesquisa descritiva quanto ao objetivo, visto que, se preocupa em descrever situações apresentadas de uma dada realidade (GIL, 2008). Desenvolveu-se em uma escola da rede pública estadual de Pernambuco, de jornada integral, mais precisamente situada no Agreste Meridional, na disciplina de Química, nas turmas de segundo e terceiro ano do ensino médio. Participaram dos procedimentos da sequência didática (SD) 43 estudantes do segundo ano e 36 do terceiro ano.

A sequência didática (SD) é "[...] um conjunto de atividades ordenadas, estruturadas e articuladas para a realização de certos objetivos educacionais, que têm um princípio e um fim, conhecidos tanto pelos professores como pelos alunos" (ZABALA, 1998, p. 18). Qualquer que seja a estratégia planejada faz-se necessário ter bem definidos os objetivos e as etapas que podem ser construídos de forma colaborativa (professores e estudantes).

A pesquisa constituiu-se de quatro etapas, a primeira é abordagem sobre infográficos, a segunda é a operacionalização, momento em que os estudantes constroem os infográficos, a terceira é da exposição e avaliação, e quarta etapa culmina com aplicação do questionário. $\mathrm{O}$ questionário foi constituído por apenas cinco questões fechadas.

Todos os 43 estudantes do segundo ano e os 36 do terceiro participaram das três primeiras etapas. No entanto, para responder ao questionário foram escolhidos por amostragem aleatória, 15 estudantes do segundo ano e 15 do terceiro ano. A análise dos dados ocorreu de maneira descritiva e por amostragem. As etapas que compreendem toda a sequência didática estão pormenorizadas a seguir:

Primeira etapa da SD - Inicialmente foi realizada uma breve exposição e apresentação de infográficos, por conseguinte, foi explicado como fazê-los utilizando o aplicativo Canva no celular ou no computador.

Segunda etapa da SD - Nas turmas de segundo ano os estudantes foram divididos em grupo de cinco pessoas e designados a pesquisarem temas relacionados ao estudo dos tipos de gases que fazem parte do nosso cotidiano.

Nas turmas de terceiro ano os estudantes também foram divididos em grupo, e abordaram em seus infográficos temas sobre as drogas lícitas e ilícitas, seguindo alguns critérios, como: origem, formas de uso, dependência, efeitos no organismo.

A partir da pesquisa teriam que criar os infográficos obedecendo aos critérios estabelecidos, mas usando a criatividade. A zona de desenvolvimento proximal (ZDP) atua nesse momento de mediação com outros sujeitos para estabelecer relações de aprendizagem, desenvolvendo assim processos psíquicos individuais mais complexos (OSTERMANN; CAVALCANTI, 2011).

Terceira etapa da SD - Os infográficos foram apresentados nas respectivas turmas e depois expostos nos corredores da escola para apreciação e conhecimentos dos demais educandos.

Os infográficos foram apresentados nos seminários, sendo por isso, também, instrumento avaliativo, que nesse caso, participou da composição da avaliação do grupo. Tal atividade gerou uma pontuação que foi utilizada pela professora como 
uma das atividades avaliativas exigidas pelo sistema educacional da rede estadual de Pernambuco.

A avaliação consistia na objetividade, clareza e domínio de conteúdo no seminário, cuja pontuação era em parte individual e o restante composta pela avaliação do infográfico nos critérios definidos antes da confecção, além da criatividade e organização do mesmo.

Quarta etapa da SD - Aplicação de questionário para investigação, por amostragem, das turmas, com as quais a estratégia foi aplicada para identificar a percepção dos estudantes sobre o uso de infográficos como recurso para auxiliar a aprendizagem.

\section{RESULTADOS E DISCUSSÃO}

Diante das estratégias aplicadas na SD e do questionário respondido são tecidos os resultados dessa pesquisa. $O$ trabalho contou com a participação de 43 estudantes do segundo ano e 36 do terceiro que participaram dos procedimentos realizados. No entanto, para responder o questionário, apenas uma amostra para representar o perfil das respectivas turmas foi adotada. Dessa maneira, 15 estudantes do segundo ano e 15 do terceiro ano representaram o perfil da turma. Os dados obtidos através do questionário estão representados nas tabelas 1, 2, 3 e 4.

$\mathrm{Na}$ etapa inicial de abordagem através de questionamentos informais os estudantes do segundo ano e do terceiro, em sua maioria, não sabiam construir um infográfico e alguns nem conheciam. Na segunda etapa que foi da construção dos infográficos mediante a pesquisa e os critérios estabelecidos observou-se que os estudantes tiveram um pouco de dificuldade em construir, e alguns preferiram utilizar outros programas para a elaboração. A princípio foi pedido para que criassem no Canva, mas alguns preferiram outros programas.

Na sequência das etapas, a terceira foi a que culminou na apresentação dos infográficos impressos. Essa consistiu em um seminário no qual os estudantes usaram o recurso gráfico para apresentação. Além de servir como instrumento auxiliar no processo de discussão, também foram avaliados, compondo a pontuação dada no seminário que consistia em dois $(2,0)$ pontos para exposição oral e mais dois $(2,0)$ pela criação e apresentação dos infográficos pelos grupos. Após todas as exposições os infográficos foram fixos nas paredes da sala de Química, bem como nos corredores da escola campo da pesquisa.

Na última etapa, na qual se recorreu a um questionário com cinco questões todas fechadas, teve-se como objetivo analisar a percepção dos estudantes sobre a criação e utilização de infográficos como recurso para auxiliar a aprendizagem. As análises foram feitas e colocadas em tabelas para traçar um perfil representativo por amostra das turmas do segundo e terceiro ano. No primeiro questionamento levantou-se o conhecimento que os estudantes tinham sobre infográfico antes de ser apresentado pelo professor, o resultado é evidenciado na tabela 1. 
Tabela 1 - Conhecimento prévio dos estudantes sobre infográfico

\begin{tabular}{ccc} 
Alternativas & $\begin{array}{c}\text { Estudantes do } \\
\text { segundo ano }\end{array}$ & $\begin{array}{c}\text { Estudantes do } \\
\text { terceiro ano }\end{array}$ \\
\hline $\begin{array}{c}\text { Conhecia, mas não sabia como } \\
\text { construir. }\end{array}$ & 07 & 11 \\
$\begin{array}{c}\text { Conhecia e sabia construir. } \\
\text { Não tinha conhecimento sobre } \\
\text { infográfico, portanto não sabia } \\
\text { construir. }\end{array}$ & 01 & 01 \\
\hline
\end{tabular}

Fonte: Autoras (2019)

Como nos mostra a tabela, 07 estudantes do segundo ano não sabiam construir um infográfico, para o terceiro ano esse número foi de 11. Quanto aos que conheciam e sabiam construir, apenas 01 estudante de cada série apontou essa resposta. Com relação aos que não conheciam e nem sabiam como construir, o número de estudantes foi: 07 para o segundo ano e 03 no terceiro ano.

Evidencia-se assim, que como aponta Feerés (1989, apud Minervini, 2005) é necessário abrir as portas para os recursos audiovisuais implicando em uma nova forma de apresentar as informações. Destarte, seja isso que falta, visto que o resultado exposto na tabela expressa que se somando os estudantes que não conheciam e não sabiam construir os infográficos, tem um total de 10, o que ressalta essa ausência dos recursos audiovisuais nas aulas. Ao considerar a tabela 2 , apresentamos a percepção da aprendizagem dos estudantes a respeito dos infográficos.

Tabela 2 - Percepção dos estudantes com relação aos infográficos e aprendizagem

\begin{tabular}{ccc} 
Alternativas & $\begin{array}{c}\text { Estudantes do } \\
\text { segundo ano }\end{array}$ & $\begin{array}{c}\text { Estudantes do } \\
\text { terceiro ano }\end{array}$ \\
$\begin{array}{c}\text { Concordo totalmente que } \\
\text { aprendizagem é facilitada pelo o } \\
\text { uso desse recurso didático. }\end{array}$ & 06 & 05 \\
\hline $\begin{array}{c}\text { Concordo parcialmente que } \\
\text { aprendizagem é facilitada pelo o } \\
\text { uso desse recurso didático. }\end{array}$ & 07 & - \\
\hline $\begin{array}{c}\text { Discordo totalmente, pois } \\
\text { aprendizagem não é facilitada } \\
\text { pelo o uso desse recurso didático. }\end{array}$ & 01 & - \\
\hline $\begin{array}{c}\text { Discordo parcialmente, pois } \\
\text { aprendizagem não é facilitada } \\
\text { pelo o uso desse recurso didático. }\end{array}$ & 01 & \\
\hline
\end{tabular}

Fonte: Autoras (2019).

Quando questionados sobre a aprendizagem percebemos que 07 estudantes do segundo ano e 10 do terceiro ano confirmam que essa aprendizagem é parcialmente facilitada pelo uso de infográficos. Podemos concordar com Meirieu (1998) e Charlot (2000) que relacionam aprendizagem a algo que faça sentido para quem deseja aprender. Dessa maneira, percebe-se que de nada adianta novas formas de ensinar ou novos recursos didáticos se esses não tiverem um significado para quem está no centro do processo. 
Corroborando com o exposto, Grymuza e Rêgo (2014) declaram que o motivo para o aprender é o que orienta a atividade para a aprendizagem, essa é uma das formas que a teoria da atividade manifesta no cenário educacional.

Na terceira e quarta questão do questionário os estudantes poderiam marcar mais de uma alternativa. A questão três mencionava alguns aspectos para a elaboração de infográficos, como as opções que estão apresentadas na tabela 3.

Tabela 3 - Aspectos identificados por estudantes ao criar os infográficos

\begin{tabular}{ccc} 
Alternativas & $\begin{array}{c}\text { Estudantes do } \\
\text { segundo ano }\end{array}$ & $\begin{array}{c}\text { Estudantes do } \\
\text { terceiro ano }\end{array}$ \\
Autonomia & 11 & 07 \\
Criatividade & 14 & 15 \\
Empatia & 04 & - \\
Criticidade & 03 & 01 \\
Caráter investigativo & 04 & 04 \\
Curiosidade & 14 & 12 \\
\hline
\end{tabular}

Fonte: Autoras (2019).

Com relação às habilidades desenvolvidas na construção dos infográficos, destacou-se em primeiro lugar a criatividade, seguida da curiosidade e da autonomia. No tocante ao caráter investigativo atingiram o mesmo número de respostas, 04 em cada série. Esses aspectos apresentados caracterizam-se como habilidades centradas nas emoções e na necessidade associada as aptidões mentais como proposto na teoria da atividade (ASBAHR, 2005).

A alternativa com o termo empatia foi proposta, tendo em vista que, quem construísse o infográfico tivesse a preocupação de se colocar no lugar de quem faria a leitura do recurso; de pensar como seria a melhor forma de organizar as ideias e se ficaria claro para quem as lessem. Mediante esses esclarecimentos, apenas 04 estudantes do segundo ano elegeram esse item, enquanto nenhum do terceiro ano o apontou. Considerando as dificuldades na criação de infográficos encontramos na tabela 4, os seguintes:

Tabela 4 - Dificuldades encontradas na criação de infográficos

\begin{tabular}{ccc}
\hline Alternativas & $\begin{array}{c}\text { Estudantes do } \\
\text { segundo ano }\end{array}$ & $\begin{array}{c}\text { Estudantes do } \\
\text { terceiro ano }\end{array}$ \\
\hline $\begin{array}{c}\text { Organizar as informações nos } \\
\text { modelos dos aplicativos/ } \\
\text { programas. }\end{array}$ & 07 & 10 \\
\hline $\begin{array}{c}\text { Sintetizar as informações } \\
\text { pesquisadas no infográfico. }\end{array}$ & 02 & 03 \\
\hline $\begin{array}{c}\text { Procurar um modelo que mais se } \\
\text { adequasse ao trabalho proposto. }\end{array}$ & 05 & 02 \\
\hline Não tive dificuldades. & 03 & 01 \\
\hline
\end{tabular}


No relato quanto as dificuldades que perpassaram à criação dos infográficos, a alternativa 'Organizar as informações nos modelos dos aplicativos/ programas' foi a que se apresentou como maior dificuldade, seguida das 'Procurar um modelo que mais se adequasse ao trabalho proposto' e 'Sintetizar as informações pesquisadas no infográfico', nesse tocante demonstra-se que os estudantes precisam interagir mais com essa ferramenta, pois, o hábito pode levar ao aperfeiçoamento.

Como bem salientam Muñoz Carril, Fuentes Abeledo e González Sanmamed (2012), não é só saber a mensagem do infográfico, mas os aspectos de organização, de recursos que devem ser inseridos para que facilitem a compreensão do leitor. Ainda nesse viés, adentramos a psicologia histórico cultural a qual considera o homem como ser proativo (PRESTES; LOPES, 2015). Ou seja, no campo educacional é quando o estudante se torna responsável por sua aprendizagem.

Com relação à quinta e última questão, 15 estudantes do terceiro ano responderam que poderia ser adotado nas aulas ou trabalhos de outras disciplinas, enquanto 14 do segundo ano também concordaram com essa resposta. Apenas 01 dessa série não concordou. Diante dessa resposta, entendemos que não houve significado para o estudante, que o propósito de realizar a atividade pode ter sido um "motivo- estímulo" ou "motivo compreensível", o que quer dizer que o infográfico não teve sentido para ele, logo, pode ter feito simplesmente como mais uma tarefa escolar (GRYMUZA; RÊGO, 2014; LEONTIEV, 2006).

O que se observou é que poucos estudantes conheciam infográficos, os que sabiam nunca tinham realizado atividades que promovessem a criatividade utilizando esse instrumento. Em conversa informal, disseram que gostaram de utilizar infográficos, mas que acharam um pouco difícil manejar o Canva, por ser a primeira vez que estavam utilizando. Dessa forma, alguns recorreram ao PowerPoint por considerarem mais familiarizados com o programa.

Posteriormente, alguns estudantes acabaram adotando essa ferramenta para produzir outros infográficos nas demais disciplinas e em atividades como as ações do grêmio estudantil, o que pode ser considerado uma aprendizagem com significado. Como aduz Leontiev (1978) as significações fazem parte da sociedade, mas é o sentido que traz significado pessoal, isso indica que a atividade centra-se o motivo pelo qual o sujeito a realiza, assim utilizar um infográfico para apresentar conteúdos de outras disciplinas ou de outras situações escolares imbui de significação para o indivíduo.

Para Querol, Cassandre e Bulgacov (2014) quando se internaliza determinado objeto é que desenvolvemos novas aptidões. Nas figuras 2 e 3, apresentamos infográficos produzidos pelos estudantes no segundo e terceiro ano do Ensino Médio sobre os temas já referidos. 
Figura 2 - Infográficos sobre temas relacionados aos tipos de gases no cotidiano

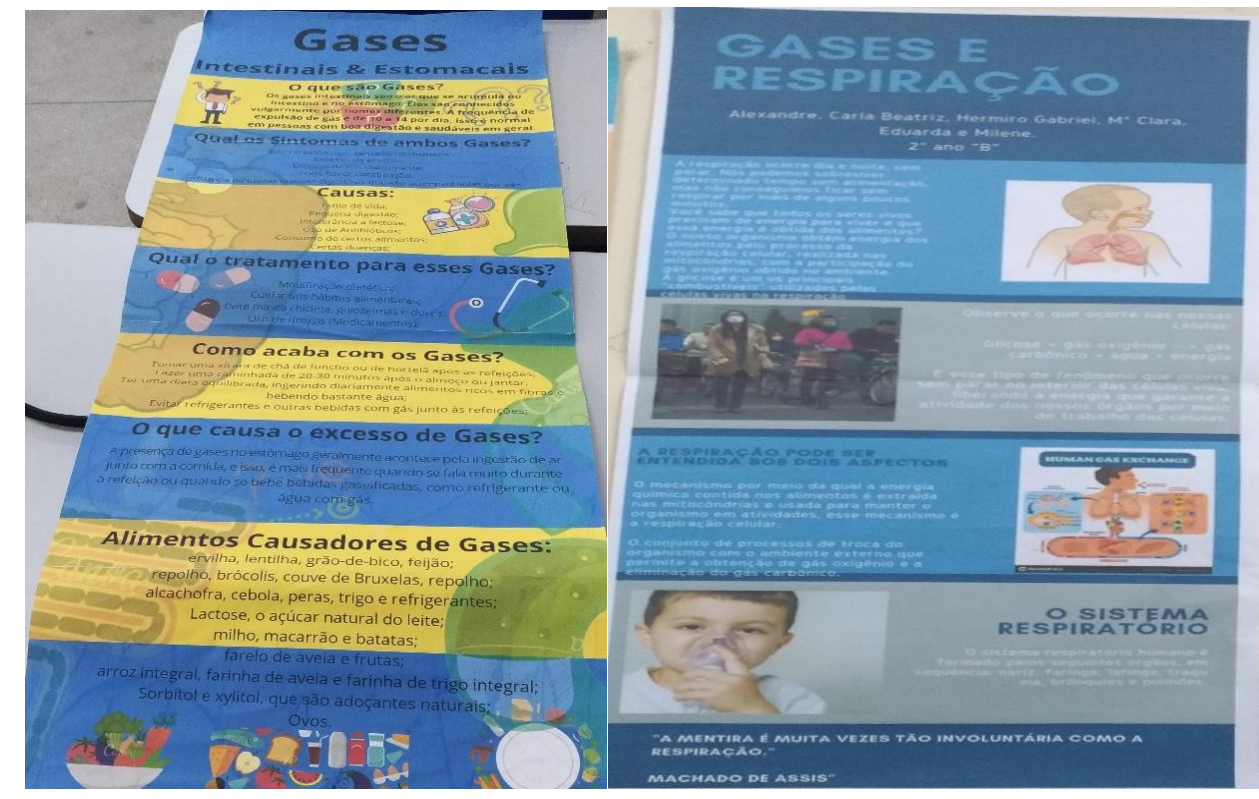

Fonte: Arquivo pessoal (2019).

Figura 3 - Infográficos sobre o tema drogas lícitas e ilícitas

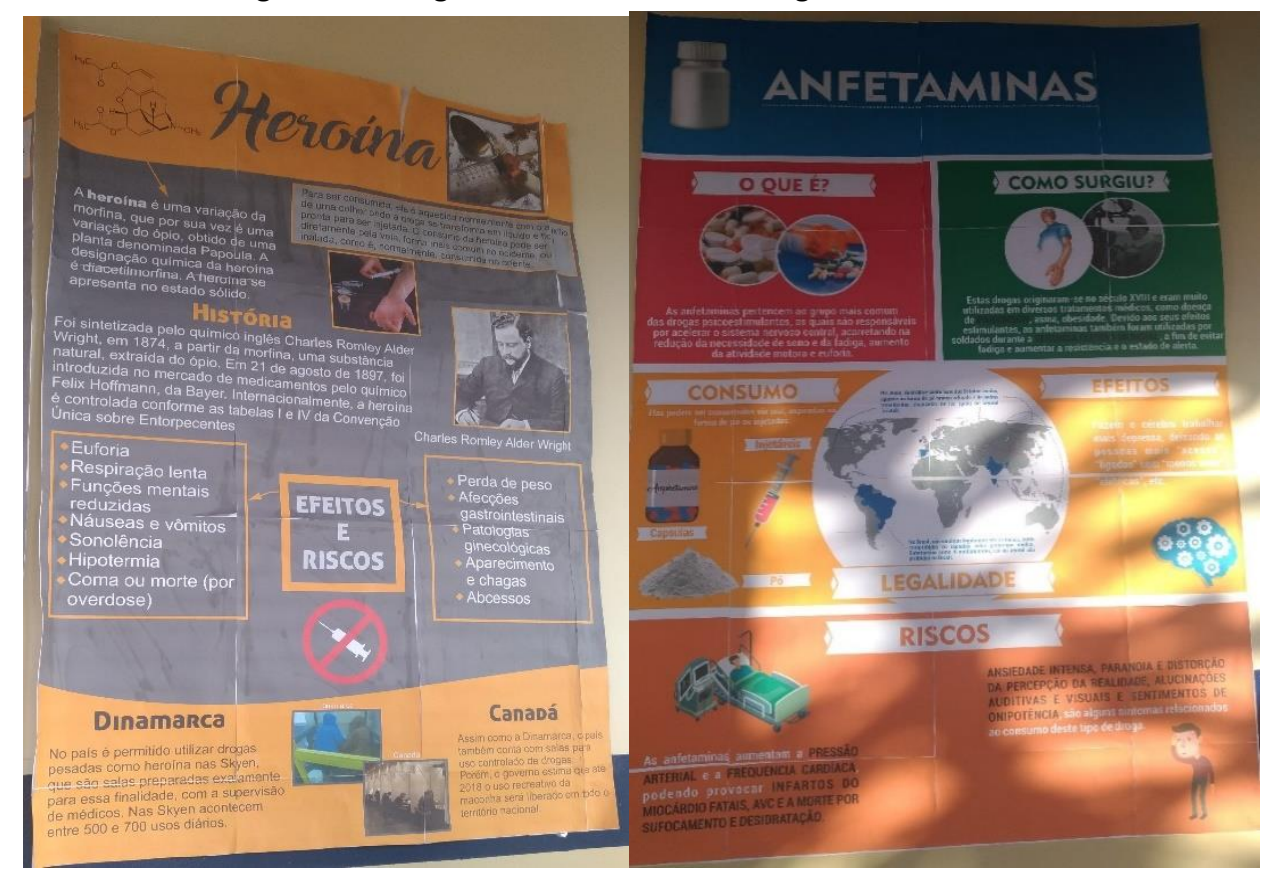

Fonte: Arquivo pessoal (2019).

Podemos perceber a aprendizagem através da maneira como os grupos organizaram o que foi pesquisado. Cada pessoa apropia-se de diferentes leituras e dessa forma, faz a relação das ideias, das especificidades e compreensões de cada componente do grupo, tornando o trabalho único. Percebemos o quanto isso é importante na formação dos educandos, apontando as habilidades e competências que são inúmeras, as quais precisam ser mais exploradas. 


\section{CONSIDERAÇÕES FINAIS}

Ao inserir recursos diferentes em atividades educacionais tem-se a intenção de melhorar o processo de ensino, mas principalmente de aprendizagem. A criação e utilização de infográfico por estudantes de duas turmas de ensino médio, demonstrou que trazer esse recurso para a sala de aula pode promover engajamento, colaboração e motivação.

A pesquisa mostrou que 07 educandos do segundo e 11 do terceiro conheciam sobre infográficos, mas não sabiam construí-lo antes das etapas aplicadas. Enquanto 07 do segundo e 03 do terceiro não conheciam, por isso, não sabiam construir. Revela-se, pois, que a utilização de infográfico como recurso didático auxilia de forma parcial a aprendizagem, de acordo com a percepção de 7 estudantes do segundo ano e de 10 do terceiro ano.

Autonomia, curiosidade e criatividade foram os aspectos mais apontados na criação de infográficos, o que determina uma produção mais mediada em que o estudante é o autor da sua aprendizagem por considerar aparentemente a atividade com significado. Considerando as dificuldades, a organização das informações nos modelos do aplicativo/programa foram as mais citadas.

Como se pode notar, o uso de infográficos tem potencial de colaborar para o processo de aprendizagem, denotando uma ferramenta a mais para as situações didáticas, e consequentemente mais um instrumento avaliativo. Os infográficos apresentam a linguagem visual para atrair o leitor, do mesmo modo, a construção requer empenho, uma junção de emoções e processos cognitivos para que se tenha significado aquilo que se aprende (ASBAHR, 2005; LEONTIEV, 2006).

Os estudantes sentem-se atraídos por essa nova forma de conduzir o aprendizado, no entanto, ainda estão pouco habituados ao recurso, o que aflora no conhecimento que o professor deve ter para orientar a construção ou até a utilização de infográficos nos processos de ensino e aprendizagem. É importante perceber que se encontram ainda dificuldades na criação, mas que essas podem ser superadas na medida em que se aplicam os infográficos para as diferentes atividades educacionais.

Portanto, emerge como uma ferramenta inovadora para o processo educativo, salientando que o uso desse material necessita ser mais explorado, uma vez que, integrá-lo em situações didáticas habitua os estudantes a interagirem com o instrumento e a implementarem em outras demandas escolares. 


\title{
INFOGRAPHICS AS AN AUXILIARY RESOURCE FOR THE LEARNING PROCESS OF HIGH SCHOOL STUDENT
}

\begin{abstract}
Changes observed in the education scenario through the use of media resources envision the multiple ways to learn and disseminate knowledge, seeking to adapt the tools that have emerged in other contexts to be applied in the classroom, such the infographics. In this way, the research aims to analyze the students' perception about the creation and use of infographics as a resource to assist learning. It is based on the following authors: Charlot (2000), Meireu (1998), Horn (1998), Colle (2004), Behrens (2005), Minervini (2005), Schmitt (2006), Leontiev (1978; 2006) among others. As for the methodology, it is a descriptive research, which was developed in a public school in the state of Pernambuco, in the discipline of Chemistry, in the second and third year of high school. The study used a didactic sequence (SD) according to Zabala (1998). Participated in the SD 43 second year students and 36 third year. The SD was proposed in four stages, the first presents an approach to infographics, the second is the practical moment when students build the infographics, the third is the exposure of the constructed infographics and the evaluation process and the fourth stage culminates with application of the questionnaire with five objective questions. All students participated in the SD, except for the questionnaire stage, which was applied by sampling with 15 second year students and 15 third year students. The results showed that 07 students of the second and 11 of the third knew about infographic, but did not know how to build it; regarding the resource to assist learning, 07 students from the second and 10 from the third responded that it partially helps; with regard to the aspects most pointed out in the creation of infographics, the most cited were: autonomy, curiosity and creativity. The difficulties expressed were in relation to the organization of information in the models of apps / programs. Therefore, infographics emerges as an innovative tool, as students are attracted to this new way of conducting learning, however, they are still not used to the resource, which requires more exploration to integrate it into school situations.
\end{abstract}

KEYWORDS: Learning. Infographics. Didactic Resource. 


\section{REFERÊNCIAS}

ALVAREZ, A. M. T. Infografia na Educação: contribuições para o pensar crítico e criativo 2012. Tese (Doutorado em Educação) Pontifícia Universidade Católica de São Paulo. São Paulo, 2012, $312 f$.

ASBAHR, F. S. F. A pesquisa sobre a atividade pedagógica contribuições da teoria da atividade. Revista Brasileira de Educação. n. 29, mai./jun. 2005.

BEHRENS, M. A. O paradigma emergente e a prática pedagógica. Petrópolis: Vozes, 2005.

CAIRO, A. Infografia 2.0: Visualización Interactiva de Información en Prensa. Espanha: Alamut, 2008.

CALEGARI, D. A.; PERFEITO, A. M. Infográfico: possibilidades metodológicas em salas de aula de Ensino Médio. Entretextos, Londrina, v. 13, n. 1, p. 291-307, jan./jun. 2013. Disponível em:

<http://www.uel.br/revistas/uel/index.php/entretextos/article/viewFile/15170/1 3190>. Acesso em: 25 set. 2019.

CARVALHO, A. M. P.; PEREZ, D. G. Saber e o saber fazer do professor. In: CASTRO, A. D.; CARVALHO, A. M. P. Ensinar a ensinar: didática para a escola fundamental e média. São Paulo: Pioneira, 2001, p.107-124.

CHARLOT, B. Da relação com o saber: elementos para uma teoria. Trad. Bruno Magne. Porto Alegre: Artes Médicas Sul, 2000.

CEPEDA, C. A. El uso de las infografías didácticas en docentes de colegios secundarios. Trabajo Final de Graduación. Licenciatura en Diseño Gráfico, Universidad Siglo 21, Buenos Aires, Argentina, 2019. Disponível em: https://repositorio.uesiglo21.edu.ar/bitstream/handle/ues21/16390/CEPED A\%20CRISTIAN.pdf . Acesso em: 23 out. 2019.

COLLE, R. Infografía: tipologías. Revista Latina de Comunicación Social, Canarias, España, Laboratorio de Tecnologías de la Información y Nuevos Análisis de Comunicación Social, v.7, n. 58, p. 41- 60, jun./dez. 2004.

DIONISIO, A. P. Multimodalidade discursiva na atividade oral e escrita (atividades). In: MARCUSCHI, Luiz Antônio; DIONISIO, Angela Paiva. (orgs.). Fala e Escrita. Belo Horizonte: Autêntica, 2007. p.177-204. 
FONSECA, V. Aprender a Aprender: a educabilidade cognitiva. Porto Alegre: Artes Médicas, 1998.

GIL, A. C. Métodos e técnicas de pesquisa social. 6. ed. São Paulo: Atlas, 2008.

GOMES, C. M.; PEREIRA, D. S. G. Aspectos Neurais da Aprendizagem e a Influência do Estresse. Revista Acadêmica Licencia\&acturas, v. 2, n. 1, p. 16-23, jan./jun. 2014.

GRYMUZA, A. M.G.; RÊGO, R. G. Teoria da Atividade: uma possibilidade no de ensino de matemática. Revista Temas em Educação, João Pessoa, v. 23, n. 2, p.117-138, jul./dez. 2014.

HORN, R. E. Visual Language: Global communication for the 21st Century, Washington: Macro VU, Inc. Bainbridge Island, WA, 1998.

LEONTIEV, A. N. O desenvolvimento do psiquismo. Lisboa/Portugal: Livros Horizonte, 1978.

LEONTIEV, A. N. Uma contribuição à teoria do desenvolvimento da psique infantil. In: VIGOTSKI, L. S.; LURIA, A. R.; LEONTIEV, A. N. Linguagem desenvolvimento e aprendizagem. Traduação: Maria da Penha Villalobos, 10 ed. São Paulo: Ícone, 2006.

LIMA, G. A.; CATELÃO, E. M. Infográfico: produção e possibilidades no uso educacional do ensino de geografia. Ensino e Tecnologia em Revista, Londrina, v. 3, n. 1, p.1-20, jan./jun. 2109.

LUCAS, R. J. L. Show, don't tell. A infografia como forma gráfico-visual: da produção do conceito à produção de sentido. Tese (Doutorado em Comunicação) Universidade Federal de Pernambuco, Recife, 2011, $419 f$.

MATTAR, J. Web 2.0 e redes sociais na educação. São Paulo: Artesanato educacional, 2013.

MEIRIEU, P. Aprender... sim, mas como? Tradução de Vanise Pereira Dresch; consultoria de Maria da Graça Souza Horn e Heloísa Schaan Solassi. 7. ed. Porto Alegre: Artmed, 1998. 
MINERVINI, M. A. La infografía como recurso didáctico. Revista Latina de Comunicación Social, La Laguna, Tenerife, v.8, n. 59, 11p., jan/ jun.,2005 . Disponível em: http://www.ull.es/publicaciones/ latina/200506minervini.pdf. Acesso em: 15 set. 2019.

MORAN, J. Os novos espaços de atuação do professor com as tecnologias. In: MORAN, J.; MASSETO, M. T.; BEHRENS, M. A. Novas Tecnologias e Mediação Pedagógica. 21ae ed., São Paulo: Papirus, 2013, p. 27-29.

MOREIRA, M. A. Teorias de aprendizagem. São Paulo: EPU, 1999.

CARRIL, P. C. M.; ABELEDO, E. J. F.; SANMAMED, M. G. Necesidades formativas del profesorado universitario en infografía y multimedia. Revista de Investigación Educativa, v. 30, p. 303-321, 2012. Disponível em: < https://www.researchgate.net/publication/272208877 Necesidades formativas del profesorado universitario en infografia y multimedia > . Acesso em: 08 out. 2019.

OSTERMANN, F.; CAVALCANTI, C. J. H. Teorias de Aprendizagem. Porto Alegre: Evangraf; UFRGS, 2011.

PRESTES, Z.; LOPES, J. J. M. Lev Vigotski e a teoria histórico-cultural no Brasil: alguns relatos de pesquisas. Fractal: Revista de Psicologia, v.27, n.1, p. 2-3, jan./abr. 2015.

QUEROL, M. A. P.; CASSANDRE, M. P.; BULGACOV, Y. L. M. Teoria da Atividade: contribuições conceituais e metodológicas para o estudo da aprendizagem organizacional. Gest. Prod., São Carlos, v. 21, n. 2, p. 405-416, 2014. Disponível em: https://www.scielo.br/pdf/gp/v21n2/v21n2a13.pdf. Acesso em: 17 ago. 2020.

REINHARDT, N. V. Infografía didáctica: producción interdisciplinaria de infografías didácticas para la diversidad cultural. 2007. Dissertação (Facultad de Diseño y Comunicación) Universidad de Palermo, Argentina, 2007.

REINHARDT, N. V. Infografía Didáctica: producción interdisciplinaria de infografías didácticas para la diversidad cultural. Cuadernos 31. Centros de Estudios en Diseño y Comunicación. Argentina, p.119-191, abr. 2010.

RIBEIRO, S. A. Infografia de Imprensa: História e análise ibérica comparada. Minerva Coimbra, 2008. 
SCHMITT, V. A infografia jornalística na ciência e tecnologia: um experimento com estudantes de jornalismo da Universidade Federal de Santa Catarina. 2006. Dissertação (Mestrado em Engenharia e Gestão do Conhecimento) - Universidade Federal de Santa Catarina, Florianópolis, 2006.

JÚNIOR, W. F. S. S. O uso de dispositivos móveis em sala de aula em uma perspectiva sociocomunitária. 2017. Dissertação (Mestrado em Educação). UNISAL- Centro Universitário Salesiano de São Paulo, 2017. 99 f

TEIXEIRA, T. A presença da infografia no jornalismo brasileiro: proposta de tipologia e classificação como gênero jornalístico a partir de um estudo de caso. Revista Fronteiras, São Leopoldo, Unisinos, v. 9, n. 2, p.111-120, mai./ago. 2007.

VALENTE, J. A. O uso inteligente do computador na educação. Pátio Revista Pedagógica: Artes Médicas Sul, ano 1, n.1, p.19-21, 1997.

ZABALA, A. A prática educativa: como ensinar. Porto Alegre: Editora Artes Médicas Sul Ltda., 1998.

ZABALA, A. Os enfoques didáticos. In: COLL, C. et al. O construtivismo na sala de aula. São Paulo: Ática, 2011. p.153-196.

Recebido: 31 mar. 2020

Aprovado: 02 nov. 2020

DOI: $10.3895 /$ rbect.v13n3.11883

Como citar: OLIVEIRA, K. J. V.; CUNHA, K. S. Infográficos como recurso auxiliar do processo de aprendizagem de estudantes do ensino médio. Revista Brasileira de Ensino de Ciência e Tecnologia Ponta Grossa, v.13, n. 3, p. 324-344, set./dez. 2020. Disponível em:

<https://periodicos.utfpr.edu.br/rbect/article/view/11883>. Acesso em: XXX

Correspondência: Karla Jeane Vilela de Oliveira - biokarlalogia@gmail.com

Direito autoral: Este artigo está licenciado sob os termos da Licença Creative Commons-Atribuição 4.0 Internacional. 